\title{
In-situ synthesised hydroxyapatite-loaded films based on cellulose nanofibrils for phenol removal from wastewater
}

\author{
Vijaykiran N. Narwade $\cdot$ Rajendra S. Khairnar • Vanja Kokol
}

Received: 16 May 2017/ Accepted: 2 August 2017/Published online: 17 August 2017

(C) The Author(s) 2017. This article is an open access publication

\begin{abstract}
Phenol removal from aqueous medium was studied by the batch method using novel and fully biobased solvent-cast films prepared from cellulose nanofibrils (CNFs) and in situ synthesised hydroxyapatite (HAp) by the wet-chemical precipitation method and different concentrations of HAp precursors and weight mass of CNFs. The chemical and morphological structures of as-prepared films were investigated by X-ray diffraction, scanning electron microscopy, and energy-dispersive spectroscopy, while their physical properties were determined by water contact angle and swelling kinetic measurements. The HAp precursor leads to a surface modification of CNFs, which increases its activity by forming differently structured, sized and distributed HAp particles, influencing the phenol adsorption kinetic and capacity. The phenol adsorption was faster and higher ( $\sim 64 \mathrm{mg} \mathrm{g}^{-1}$ ) in an acidic solution ( $\mathrm{pH} \mathrm{2)}$ compared to the original phenol solution $\mathrm{pH}(\mathrm{pH} 7.4$, $\sim 30 \mathrm{mg} \mathrm{g}^{-1}$ ) using films with unevenly-distributed and positively-charged calcium-richer HAp particles
\end{abstract}

V. N. Narwade · R. S. Khairnar $(\bowtie)$

School of Physical Sciences, Swami Ramanand Teerth

Marathwada University, Nanded, MS 431606, India

e-mail: rk2kin@yahoo.com

V. N. Narwade · V. Kokol ( $\square)$

Institute for Engineering Materials and Design, Faculty of

Mechanical Engineering, University of Maribor,

Smetanova ul. 17, 2000 Maribor, Slovenia

e-mail:vanja.kokol@um.si synthesised on the CNFs' surface, being reflected also in its higher water swelling properties, compared to their hybrid counterparts. The phenol adsorption is identified to follow pseudo-second order kinetic and intra-particle diffusion models. A highly-efficient reusing ability of the selected film with $86 \%$ adsorption capacity of the initial value at the third sequential regeneration cycle, is also confirmed. A super-hydrophilic nature of the films with high water-diffusing and transport properties, as well as low swelling, indicates their potential in the development of highlyeffective adsorbents and, potentially, filter membranes for water purification.

Keywords Cellulose nanofibrils · Hydroxyapatite . Films · Phenol adsorption $\cdot$ Film reusing

\section{Introduction}

Phenol is one of the first compounds inscribed into the list of priority pollutants (Bruce et al. 1987), with the standard limit of $1 \mathrm{mg} / \mathrm{L}$ in drinking water. Phenol and its derivatives (Michalowicz and Duda 2007) are organic pollutants existing in wastewater from the discharge of such chemical industries as resin manufacturing, gas and coke manufacturing, tanning, textile, plastic, rubber, pharmaceutical, and petroleum, and particularly those dealing with end products such as paper and pulp, pesticides, and dyes. Phenols are 
also present in domestic effluents and vegetation decay.

In view of the wide prevalence of phenol and its derivatives in different wastewaters, as well as their toxicity to human and animal life even at low concentrations, its removal before discharging the wastewater into water reservoirs has, thus, increasingly become a significant environmental concern. Treatment of wastewater containing phenol has been studied by various methods such as oxidation with ozone/hydrogen peroxide (Esplugas et al. 2002), biological methods (Ehrhardt and Rehm 1985), ion exchange (Lin et al. 2009), electrochemical oxidation (Ajeel et al. 2017; Zaky and Chaplin 2014), reverse osmosis ( $\mathrm{Li}$ et al. 2017), photocatalytic degradation(Koyama et al. 1994), coagulation flocculation (Yang et al. 2015), and adsorption (Caetano et al. 2009; Gupta et al. 2004; Jain et al. 2004; Ingole and Lataye 2013; Ingole et al. 2017; Dhorabe et al. 2016a, 2016b), as well as their combinations. The majority of these methods have shown relatively low efficiency (4.5-303 $\mathrm{mg} \mathrm{g}^{-1}$ ) and, thus, the adsorption process still remains the best, as it can generally remove all types of phenols, and the effluent treatment is convenient because of its simple design and easy operation. In this framework, activated carbon (Dabrowski et al. 2005; Özkaya 2006; Kumar et al. 2007; Din et al. 2009; Kilic et al. 2011; Dhorabe et al. 2016a; Ingole and Lataye 2013; Ingole et al. 2017; Sáenz-Alanís et al. 2017; Lorenc-Grabowska 2016; Srivastava et al. 2006) is still the most widely used material, although it has disadvantages, such as high initial cost, high regeneration cost, and the generation of carbon fines, due to its brittle nature. Alternative adsorbents include naturally occurring materials such as different powder-based earth minerals (zeolite, bentonite, clinoptilolite) (Banat et al. 2000; Mangrulkar et al. 2008; Sprynskyy et al. 2009), polymeric resins (Caetano et al. 2009; Lin and Juang 2009; Juang and Shiau 1999; Li et al. 2002; Vázquez et al. 2007), polysaccharides (chitin, chitosan) (Li et al. 2009; Dursun and Kalayci 2005; Ahmaruzzaman and Sharma 2005), or other inexpensive and renewable biomassresource materials (coconut shell, rice husk, ash, beet pulp etc.) (Din et al. 2009; Ahmaruzzaman 2005; Chaudhary and Balomajumder 2014; Dursun et al. 2005). However, many of them have poor adsorption capacity (1.7-131.5 $\mathrm{mg} \mathrm{g}^{-1}$ ) as compared to activated carbons, and some of them are not really low-cost materials suitable for extensive use. Efforts are, therefore, still needed to have materials that would have a relatively high-enough adsorption capacity and could be reused and recycled easily, or even discharged as bio waste (composted or used as fertilizer) after the final usage Recent advances in nanoscale science and engineering suggest that many of the current problems involving water quality could be diminished greatly using nanostructured materials and particles that exhibit good adsorption efficiency, especially due to their higher surface area and greater amount of active sites for interaction with toxic pollutants. However, the potential eco-toxicological impact of nanoparticles, the search for novel, eco-friendly materials for water purification with low cost, low energy input and with no hazardous by-products, is being researched extensively.

Bio-based nanocellulose as a cheap, sustainable and renewable nano-adsorbent with high surface area-tovolume ratio and extraordinary mechanical properties (Dufresne 2013), have been studying in this framework exhaustively in the last decade. Its easily functionalizable surface (associated with a huge amount of surface hydroxyl groups) allows the incorporation of chemical moieties that may increase and specify the interaction efficiency with targeted pollutants (Hokkanen et al. 2016a, b; Moon et al. 2011; Gopakumar et al. 2017). Among them, cellulose nanofibrils (CNFs) has been considered as more ductile compared to nanocrystals, thereby providing a more useful template for incorporating functionalities and for preparing selfstanding based films (Abe et al. 2007).

Apatite-based mineral materials, above all hydroxyapatite [HAp; $\mathrm{Ca}_{10}\left(\mathrm{PO}_{4}\right)_{6}(\mathrm{OH})_{2}$ ], have also become promising adsorbents for the removal of ionic dyes and heavy metal ions due to the more favourable properties, such as high chemical activity, high removal capacity, high water stability, low cost and high stability under oxidizing or reducing conditions (Corami et al. 2008; Narwade et al. 2014; Narwade and Khairnar 2017; Feng et al. 2010; Smičiklas et al. 2006). The sorption capacities of HAp for cations not only depend on metal ion concentrations, solution $\mathrm{pH}$ values, contact time and ionic species, but are also ascribed to its porous structure and crystallinity that can serve as ion channels, and, thus, increase ionic exchange and immobilization (Wen et al. 2016). In addition, HAp with low crystallinity possesses many lattice defects, which can serve as additional active sites for chemical adsorption. HAp powders are generally used as adsorbents, although it is difficult to separate them from the 
wastewaters (Zhao et al. 2014). Alternatively, HApbased porous materials have been fabricated by using polysaccharide chitosan, thus making it more suitable for industrial application (Lei et al. 2015), however, with no satisfied adsorption ability, as well as poor strength and flexibility, and high tendency to gelling due to high hydrophilicity, which limits its usage. The very recent studies show that the presynthesised HAp nanostructures can interact effectively with the microfibrillated cellulose (MFC), resulting in the enhancement of the mechanical properties of their nanocomposites due to the small size and high specific surface area, as well as relatively high adsorption capacity for both cationic $\left(\mathrm{Cr}^{4+}, \mathrm{Ni}^{2+}\right.$, $\left.\mathrm{Cd}^{2+}\right)$ and anionic $\left(\mathrm{PO}_{4}{ }^{3-}, \mathrm{NO}_{3}{ }^{-}\right)$compounds from aqueous solutions at fast adsorption rate, independent on the solution pH (Hokkanen et al. 2014, 2016b).

The objective of this work was, thus, to synthesise bio-based and highly absorbable films with no or low gelling ability for an effective removal of phenol from aqueous solutions, and possible regeneration potential. For this purpose, the films were prepared by the wetchemical precipitation method using the advantages of both highly hydrophilic and mechanically strong cellulose nanofibrils (CNFs) acting as a support, and highly sorptive HAp being synthesised in situ using HAp precursors of different concentrations and volume ratios related to the weight mass of CNFs. The microstructure, crystal structure and chemical composition of the films were studied by XRD, SEM and EDX analysis, while their physical properties were determined by water contact angle and adsorption kinetic. Furthermore, the effects of $\mathrm{pH}$ value and contact time on the ability of the films to remove phenol were investigated by batch adsorption study. The performance was evaluated by applying the pseudo-first and pseudo-second order kinetics model theory to identify the kinetic parameters, and an intraparticle diffusion model to define the diffusion mechanism of adsorption. Finally, the phenol-desorption and reusing ability of the films was examined.

\section{Experimental}

Materials used

Cellulose nanofibrils (CNFs) were supplied by the University of Maine, Process Development Center in the USA (http://umaine.edu/pdc/nanofiber-r-d/). Diammonium hydrogen phosphate $\left[\left(\mathrm{NH}_{4}\right)_{2} \mathrm{HPO}_{4}\right.$, Sigma Aldrich, purity $99.00 \%$ ], calcium nitrate tetrahydrate [ $\left(\mathrm{Ca}\left(\mathrm{NO}_{3}\right)_{2} 4 \mathrm{H}_{2} \mathrm{O}\right.$, Sigma Aldrich, Purity 99.00\%], phenol [ $\left(\mathrm{C}_{6} \mathrm{H}_{5} \mathrm{OH}\right.$, Sigma Aldrich, Purity $\left.\left.99.99 \%\right)\right]$, ammonia solution [25\% $\left(\mathrm{NH}_{4} \mathrm{OH}\right.$, Merck Millipore)], and hydrochloric acid $[\mathrm{HCl}$, Merck Millipore] were used as received, without further purification. Commercial hydroxyapatite [HAp; CAS no.-12167-74-7] was purchased from Sigma-Aldrich.

\section{HAp synthesis}

HAp was synthesised by the wet chemical precipitation method using $1 \mathrm{M}$ calcium nitrate tetrahydrate and $0.6 \mathrm{M}$ di-ammonium hydrogen phosphate as precursors in molar concentrations to have the theoretical ratio of $\mathrm{Ca} / \mathrm{P}$ in 1.66 (Chavan et al. 2010). The $\mathrm{pH}$ of the reaction was maintained at 10 using an ammonia solution. The precipitation process is carried out by dropwise addition of both precursor solutions. The process is carried out under continuous stirring of $150 \mathrm{rpm}$ at $80{ }^{\circ} \mathrm{C}$ for $4 \mathrm{~h}$, followed by ageing for about $24 \mathrm{~h}$. The white precipitate is then washed 3-4 times with double distilled water to remove the rest of the precursors, and dried in an air oven at $60{ }^{\circ} \mathrm{C}$.

Synthesis of HAp in the presence of CNFs and film formation

The CNF-HAp films were prepared by the wetchemical precipitation method using $0.6 \mathrm{M}$ di-ammonium hydrogen phosphate and $1 \mathrm{M}$ calcium nitrate tetrahydrate as precursors in a $\mathrm{Ca} / \mathrm{P}$ ratio of 1.66 (Chavan et al. 2010) for HAp synthesis in situ, and different weight masses of CNFs, as presented in Table 1. The CNF was added to the di-ammonium hydrogen phosphate solution and stirred to obtain a uniform mixture, before adding it to the calcium nitrate tetrahydrate solution. The $\mathrm{pH}$ of the reaction was maintained at 10 using an ammonia solution. During this process, the white precipitate starts to deposit on the sides of the beaker. The solution is kept stirring for $4 \mathrm{~h}$ and, later on, kept for a gelation for $24 \mathrm{~h}$. The precipitate dispersion is then washed several times with distilled water to maintain its $\mathrm{pH}$ neutrality. $20 \mathrm{~mL}$ of the residual sample is then transferred to Petri dishes and heated to $60{ }^{\circ} \mathrm{C}$ overnight to form the films of $0.34 \pm 0.02 \mathrm{~mm}$ thickness. 
Table 1 Composition of CNF-based films prepared without and with HAp precursors (A: Calcium nitrate tetrahydrate, B: Diammonium hydrogen phosphate), and corresponding nomenclature used

\begin{tabular}{llllll}
\hline Sample no. & HAp precursors $(\mathrm{mL})$ & Amount of A $(\mathrm{g})$ & Amount of B $(\mathrm{g})$ & CNF $(\mathrm{g})$ & Sample name \\
\hline 1 & 25 & 2.94 & 0.98 & 0.5 & $0.5 \mathrm{CNF}-25 \mathrm{HAp}$ \\
2 & 25 & 2.94 & 0.98 & 1.5 & $1.5 \mathrm{CNF}-25 \mathrm{HAp}$ \\
3 & 11.76 & 3.94 & 0.5 & $0.5 \mathrm{CNF}-100 \mathrm{HAp}$ \\
4 & 100 & 11.76 & 3.94 & 1.5 & $1.5 \mathrm{CNF}-100 \mathrm{HAp}$ \\
5 & 100 & & & 0.5 & $0.5 \mathrm{CNF}$ \\
6 & - & & & 1.5 & $1.5 \mathrm{CNF}$ \\
\hline
\end{tabular}

\section{Film characterization}

The crystallinity and crystallite size of the HAp synthesised in the composite films was determined by using the X-ray diffraction technique (XRD). The Xray equatorial diffraction patterns of the films were obtained with a Rigaku MiniFlex 2X-ray diffractometer using $\mathrm{Cu}$ Ka radiation $(\lambda=0.1541 \mathrm{~nm})$ at the operating voltage and current of $40 \mathrm{kV}$ and $40 \mathrm{~mA}$, respectively, at room temperature within a $2 \theta$ value ranging from $10^{\circ}$ to $60^{\circ}$. The size (nm) of HAp crystals was evaluated along the $(002)$ direction $\left(2 \theta\right.$ of $\left.\sim 26^{\circ}\right)$ using the Debye-Scherer's formula (Panda et al. 2003):

$\mathrm{D}=\frac{\mathrm{k} \lambda}{\beta \cos \theta}$

where $\mathrm{k}$ is the Scherer constant (0.89), $\lambda$ is the $\mathrm{X}$-ray wavelength $(0.15418 \mathrm{~nm})$ in the case of $\mathrm{Cu} \mathrm{K \alpha}$ radiation, $\beta$ is the full width at half-maximum (FWHM) of the diffraction peak in radians, and $\theta\left(^{\circ}\right)$ is the corresponding Bragg angle.

Scanning electron microscopy (SEM) imaging, coupled with energy dispersive spectroscopy (EDX), was performed using the UltraPlus (Zeiss, Germany) microscope to evaluate the films' morphology and microstructure. The samples were coated with a platinum layer using an ion sputter PECS-precision etching coating system, model 682 (Gatan US).

Contact angle measurements of the films were assessed by using an SCA20 contact angle measurement system from Dataphysics (Germany). All measurements were conducted at room temperature on two independent surfaces with an MQ water and volume of $3 \mathrm{~mL}$. Each value was the average of at least eight drops of liquid per surface.

The kinetic of miliQ water adsorption was performed by the gravimetrical method at room temperature and different incubation times, and expressed by the swelling ratio using the following formula (Zhang et al. 2014):

Swelling ratio $(\%)=\frac{\mathrm{M}_{\mathrm{s}}=\mathrm{M}_{\mathrm{d}}}{\mathrm{M}_{\mathrm{d}}} * 100$

where $M_{d}$ and $M_{s}$ represent the weight of the dry and swollen samples, respectively. The average values, as well as the standard deviation of the mean values, were calculated from at least three individual measurements.

Evaluation of phenol adsorption and desorption

The film samples of $1 \mathrm{~cm}(\mathrm{~L}) \times 1.5 \mathrm{~cm}(\mathrm{~W})$ dimension were incubated with $50 \mathrm{mg} \mathrm{L}^{-1}$ of phenol solution and its adsorption (capacity and kinetic) was studied at room temperature and continuous shaking (150 rpm) by varying the $\mathrm{pH}$ of the starting solutions, the $\mathrm{pH} 2$ being adjusted with $0.1 \mathrm{M} \mathrm{HCl}$ and $\mathrm{pH} 7.4$ as generated by the phenol itself. The concentration of phenol in the solution was examined at $270 \mathrm{~nm}$ by means of UV-Vis spectroscopy using a plate-reader equipped with a Tecan UV-Vis spectrophotometer. The phenol adsorption capacity $\left(\mathrm{q}_{\mathrm{e}}, \mathrm{mg} \mathrm{g}^{-1}\right)$ was calculated according to the following formula (Narwade et al. 2017):

$\mathrm{q}_{\mathrm{e}}=\frac{\mathrm{v}}{\mathrm{m}}\left(\mathrm{c}_{\mathrm{i}}-\mathrm{c}_{\mathrm{t}}\right)$

where $\mathrm{V}(\mathrm{L})$ is the volume of phenol solution, $\mathrm{m}(\mathrm{g})$ is the mass of the film, $\mathrm{C}_{\mathrm{i}}\left(\mathrm{mg} \mathrm{L}^{-1}\right)$ is the initial phenol concentration, and $\mathrm{C}_{\mathrm{t}}\left(\mathrm{mg} \mathrm{L}^{-1}\right)$ is the concentration after certain immersion $\mathrm{t}$ (min). All the experiments were carried out in triplicate to estimate the standard deviation. The amount of phenol that was adsorbed on a film $\left(\mathrm{q}_{\mathrm{t}}\right)$ was then plotted against the time ( $\left.\mathrm{t}\right)$ and 
analysed using various models to obtain the kinetic parameters of adsorption and a fitted intra particle diffusion model to identify the diffusion mechanism.

The phenol-adsorbed films were also studied for desorption by being shaken in miliQ water $(18.2 \mathrm{~m} \Omega)$ for up to $3 \mathrm{~h}$ until reaching the equilibrium of phenol desorbed. The percentage of desorption was calculated by using the following formula (Mahto et al. 2015):

$\%$ Desorption $=\frac{\text { Phenol desorbed }\left(\mathrm{mg} \mathrm{L}^{-1}\right)}{\text { Phenol adsorbed }\left(\mathrm{mg} \mathrm{L}^{-1}\right)} \times 100$

The phenol-desorbed films were collected, rinsed again with miliQ water and reused in the next cycle of adsorption. Three repetitions were performed for each sample and the process, and the average values were calculated, as well as the Standard Deviation of the mean values.

\section{Results and discussion}

Films' characterization

The XRD patterns for both CNF and Hap, as well as composite (CNF-HAp) films, displayed in Fig. 1, indicate the formation of HAp particles with different morphologies and crystalline structures onto the

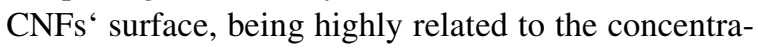
tion of HAp precursor used and their ratio to the weight mass of CNFs. The characteristic diffraction peaks of commercial HAp are located at $2 \theta$ values of $26.79^{\circ}, 32.41^{\circ}, 33.8^{\circ}, 34.71^{\circ}, 40.57^{\circ}, 47.32^{\circ}$, and $50.25^{\circ}$ corresponding to the related planes at (002), (112), (202), (211), (213), (222), (300), and (310) respectively (JCPDS card no. 09-0432) (Narwade et al. 2014). The peaks in the commercial HAp are highly oriented, it means the HAp is highly crystalline. The XRD pattern of synthesised HAp (without the presence of CNFs) also shows relatively high intensity and sharp peaks in the range of $23-39^{\circ}$ (at about $25.80^{\circ}, 31.80^{\circ}, 32.90^{\circ}$, and $34.10^{\circ}$ corresponding to (h k l) indices at (002), (211), (300), and (310), respectively), and lower intensity peaks in the range of $46^{\circ}-63^{\circ}$, which is consistent with the formation of a lower crystalline HAp structure, compared to the commercial HAp. The crystal parameters of synthesised HAp (with $\mathrm{a}=\mathrm{b}=0.941 \mathrm{~nm}$ and $\mathrm{c}=0.70 \mathrm{~nm})$, calculated from the $2 \theta$ peaks at around $32.90^{\circ}$ (300) and $25.28^{\circ}$ (002), also resemble quite well that of commercial HAp $(\mathrm{a}=\mathrm{b}=0.942 \mathrm{~nm}$ and $\mathrm{c}=0.688 \mathrm{~nm}$ ) (Narwade et al. 2017), indicating a stoichiometric HAp with the formula of $\mathrm{Ca}_{10}\left(\mathrm{PO}_{4}\right)_{6}(-$ $\mathrm{OH})_{2}$ and a hexagonal structure of the crystal lattice of around $6.55 \mathrm{~nm}$.

The films prepared with $\mathrm{CNF}$ (Fig. 1b, c) and lower precursor concentration (25HAp) still show oriented sharp peaks that resemble the peaks of synthesised HAp, being, however, a smaller size (3.26 and $4.36 \mathrm{~nm}$, respectively) and a non-stoichiometric calcium-phosphate structure. On the other hand, the films prepared with higher precursor concentration (100HAp) show a very broad XRD peak with maximum at $2 \theta$ of around $23^{\circ}$ which may be due to the overlapping of the CNF (at $2 \theta$ of $\sim 23^{\circ}$ ) and HAp (at $2 \theta$ of $\sim 25^{\circ}$ ) related peaks, and very low intensity of the HAp related peak at $2 \theta$ of $\sim 32^{\circ}$, being reflected in HAp of very poor crystallinity and low crystal sizes which are precipitated onto the surface of the CNFs. The latter effect was expressed even more in the case of the film prepared with $1.5 \mathrm{CNF}$, where no-specific peaks could be identified.

The EDX results, summarised in Table 2, indicate a stoichiometric apatite structure with a $\mathrm{Ca} / \mathrm{P}$ ratio of around 1.67 on both films prepared with higher CNF (1.5CNF) content, independent of the used precursor's concentration. On the other hand, the non-stoichiometric HAp structures were analysed in both films prepared with lower content of $\mathrm{CNF}(0.5 \mathrm{CNF})$ : A phosphorus-rich (calcium-deficient) HAp with $\mathrm{Ca} / \mathrm{P}$ ration of 1.56 on the CNF prepared with $100 \mathrm{HAp}$ was in agreement with reported literature (Fang et al. 2016), and a calcium-rich (phosphorus-deficient) with $\mathrm{Ca} / \mathrm{P}$ of 1.77 on the film prepared with $25 \mathrm{HAp}$.

The high magnification SEM images of the native $\mathrm{CNF}$ and the CNF-HAp synthesised film surfaces are shown in Fig. 2. The web-like slightly-porous net structure for the native CNF films with single $\mu \mathrm{m}$ length fibrils is displayed, as well as fibrils' bundles, being much more thick and dense in the case of the film prepared with higher CNFs' content (1.5CNF). Unevenly distributed particles of HAp were found to be present on the surface of both films prepared with lower (25HAp) concentration of precursors, while much denser and relatively homogenously distributed HAp particles on the surface are seen on the 0.5CNF- 
A

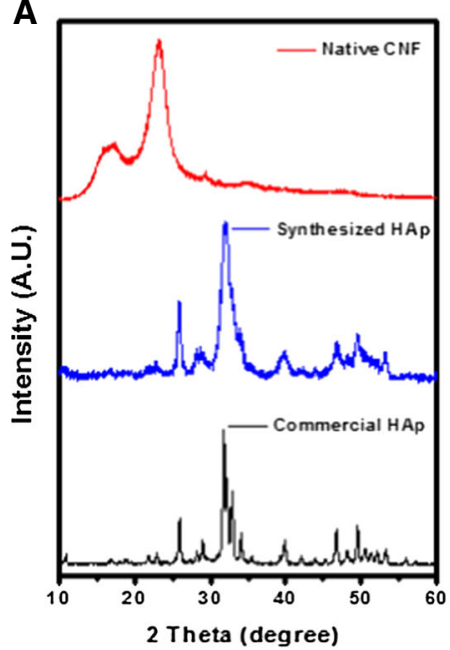

B

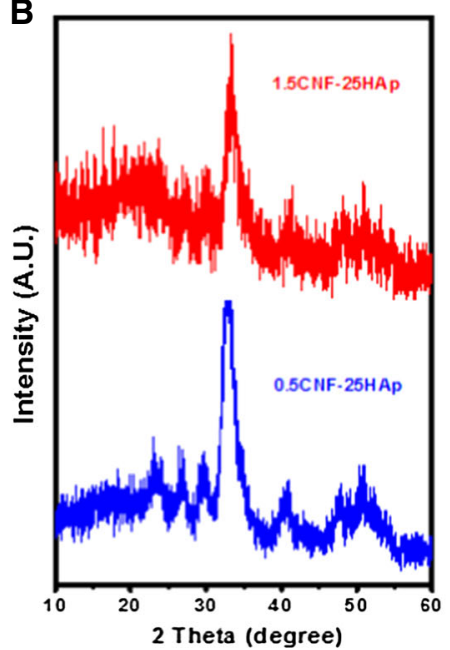

C

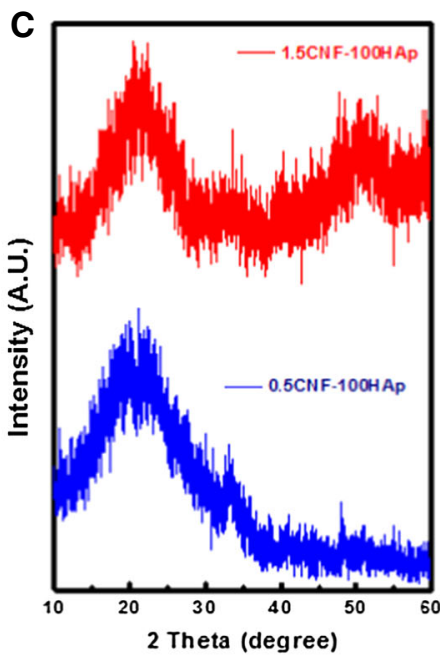

\begin{tabular}{|l|c|c|c|c|c|c|}
\hline Sample & $\begin{array}{c}\text { HAp } \\
\text { commercial }\end{array}$ & $\begin{array}{c}\text { HAp } \\
\text { synthesised }\end{array}$ & $\begin{array}{c}0.5 \mathrm{CNF}- \\
\text { 25HAp }\end{array}$ & $\begin{array}{c}1.5 \mathrm{CNF}- \\
25 \mathrm{HAp}\end{array}$ & $\begin{array}{c}0.5 \mathrm{CNF}- \\
100 \mathrm{HAp}\end{array}$ & $\begin{array}{c}1.5 \mathrm{CNF}- \\
100 \mathrm{HAp}\end{array}$ \\
\hline $\begin{array}{l}\text { Crystallite size } \\
\text { (nm) of HAp at } \\
2 \theta \text { of } \sim 26^{0}\end{array}$ & 6.0 & 6.55 & 3.26 & 4.36 & n.d. & n.d. \\
\hline
\end{tabular}

Fig. 1 XRD profile of a CNF, commercial and synthesised HAp, as well as CNF-HAp films prepared with $\mathbf{b} 25 \mathrm{~mL}$ and $\mathbf{c} 100 \mathrm{~mL}$ of HAp precursors and varying weight mass of CNFs, with corresponding crystallite size of HAp calculated (n.d. not determined)

Table 2 EDS analysis of differently prepared $\mathrm{CNF}-$ HAp films

\begin{tabular}{lllll}
\hline Elements (wt $)$ & $0.5 \mathrm{CNF}-100 \mathrm{HAp}$ & $0.5 \mathrm{CNF}-25 \mathrm{HAp}$ & $1.5 \mathrm{CNF}-100 \mathrm{HAp}$ & $1.5 \mathrm{CNF}-25 \mathrm{HAp}$ \\
\hline $\mathrm{C}(\mathrm{wt} \%)$ & $16.26 \pm 5.16$ & $47.31 \pm 8.57$ & $18 \pm 8.70$ & $36.97 \pm 3.56$ \\
$\mathrm{O}(\mathrm{wt} \%)$ & $64.35 \pm 13.24$ & $49.03 \pm 11.72$ & $61.83 \pm 14.25$ & $54.02 \pm 10.58$ \\
$\mathrm{P}(\mathrm{wt} \%)$ & $7.56 \pm 4.26$ & $1.32 \pm 2.23$ & $7.54 \pm 5.92$ & $3.40 \pm 1.96$ \\
$\mathrm{Ca}(\mathrm{wt} \%)$ & $11.84 \pm 3.21$ & $2.34 \pm 1.20$ & $12.63 \pm 4.88$ & $5.61 \pm 2.80$ \\
$\mathrm{Ca} / \mathrm{P}$ ratio & 1.56 & 1.77 & 1.68 & 1.65 \\
\hline
\end{tabular}

100HAp film, getting a ceramic type structure in the case of $1.5 \mathrm{CNF}-100 \mathrm{HAp}$.

It is obvious that the presence of CNFs induces the heterogeneous nucleation of HAp and regulates the HAp crystal structure (size and morphology), as well as its further growth. The regulation of the HAp nucleation and growth in the presence of polysaccharides (such as chitosan, alginate, heparin, carrageenan, pectins) have been studied extensively recently (Skwarek et al. 2017), indicating that the polysaccharide's functional groups, such as carboxyls $(-\mathrm{COOH})$, sulfonic $\left(-\mathrm{OSO}_{3} \mathrm{H}\right)$, amino $\left(-\mathrm{NH}_{2}\right)$, or hydroxyls $(-\mathrm{OH})$ are interacting with the HAp precursors by specific (ionic, electrostatic or coordinative) or nonspecific (hydrogen) binding. It was also found that anionic/cationic polysaccharide complexes can provide multiple nucleation sites and growth space for HAp crystals under different $\mathrm{pH}$ conditions.

However, the effects of semi-crystalline and nonhomogenously dispersed nanocellulose with abundant quantity of surface hydroxyl groups and some negative and end-located terminal carboxylic $\left(-\mathrm{COO}^{-}\right)$and sulphate $\left(-\mathrm{SO}_{3}^{2}\right)$ groups, on the mineralization of HAp crystals, has been sparsely reported. The surface of the microcrystalline cellulose (MFC) was covered completely by the HAp layers at higher concentrations of calcium or phosphorus based precursors, indicating that MFC can bind a much larger amount of HAp than its own mass, leading to nanocomposites with enhanced properties due to the small size and high 

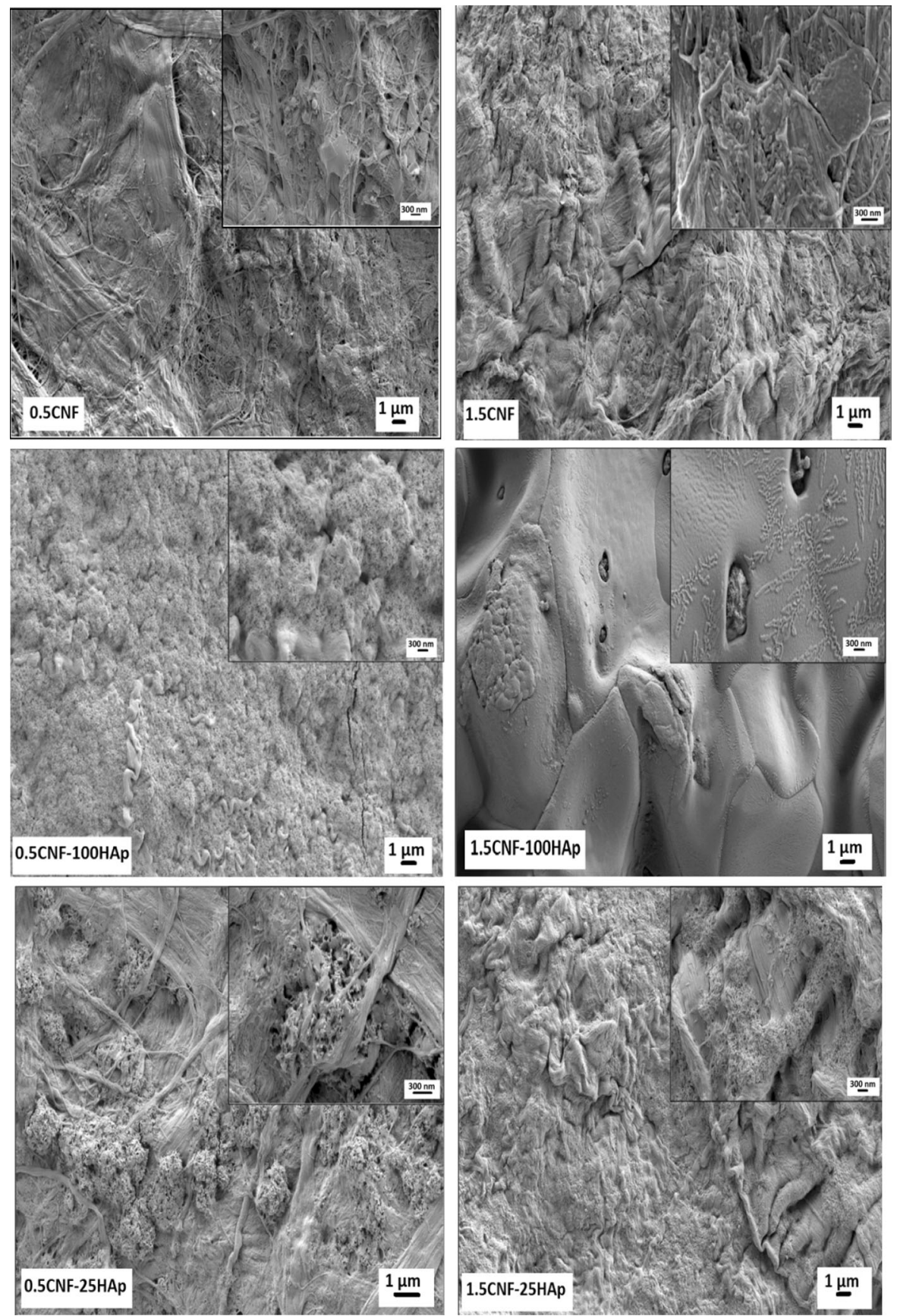

Fig. 2 SEM images of differently prepared CNF and CNF-HAp film surfaces

specific surface area, and, thus, high removal of both cations and anions independent of the $\mathrm{pH}$ of the solution (Hokkanen et al. 2016b). The biomimetic growth of HAp crystals on native and chemically prephosphorylated CNFs was also estimated by our previous research (Božic et al. 2014), indicating the binding of pre-attached phosphate groups with $\mathrm{Ca}^{2+}$ ions through coordination bonds, acting as nuclei for further growth of HAp crystals in simulated body fluid ( $\mathrm{pH} \approx 7.4$ ). While only small particles of HAp crystals are found on the native CNF surface due to the lack of effective functional groups for binding of 
calcium or phosphorus to form nuclei, quantitatively more and bigger particles were identified as phosphorylated CNF.

A schematic illustration of possible interactions between HAp precursors and CNFs during the formation of CNF-HAp composites, where the phosphatebased precursor is added before the calcium-based, is presented in Fig. 3. According to the synthesis procedure, the CNFs hydroxyl groups form a hydrogen bonding with the phosphate $\left(-\mathrm{PO}_{4}{ }^{3-}\right)$ ions from diammonium hydrogen phosphate being added as the first precursor (Daud et al. 2011), and may interact as dibasic phosphate $\left(\mathrm{Cel}-\mathrm{CH}_{2}-\mathrm{O}-\mathrm{P}(=\mathrm{O})(\mathrm{OH})_{2}\right)$ or monobasic tautomeric phosphite $\left(\mathrm{Cel}-\mathrm{CH}_{2}-\mathrm{O}-\right.$ $\mathrm{P}(\mathrm{H})(=\mathrm{O}) \mathrm{OH}$ ) with hydroxyls of cellulose (Kokol et al. 2015), after evolution of ammonia. By further addition of calcium nitrate tetrahydrate at $\mathrm{pH} 10$, the $\mathrm{Ca}^{2+}$ ions are interacting with dissociated phosphate ions available in the solution or phosphate groups preattached on the CNF, respectively, by electrostatic and/or coordination interactions, resulting in the formation of HAp nuclei and differently oriented
HAp particles after their further growth. In parallel, some electrostatic interaction between potentially present negative and end-located terminal groups ($\mathrm{COO}^{-},-\mathrm{SO}_{3}^{2}$ ) on $\mathrm{CNFs}$ can also appear with $\mathrm{Ca}^{2+}$ ions. The morphology and size of HAp particles formed in the presence of CNFs depends also on the CNF-HAp precursor's weight-mass ratio. In the case of a higher amount of precursor (100HAp), quantitatively higher interactions of $-\mathrm{PO}_{4}{ }^{3-}$ ions with $-\mathrm{OH}$ groups of CNF provide multiple nucleation sites that result in the formation of smaller HAp particles with phosphate-reach $(\mathrm{Ca} / \mathrm{P}=1.56)$ or stoichiometric $(\mathrm{Ca} /$ $\mathrm{P}=1.68)$ structure after addition of $\mathrm{Ca}^{2+}$ ions, depending on the content and, thus, the density of the CNF. By this, a partly porous $(0.5 \mathrm{CNF})$ or fully dense ceramic-type (1.5CNF) nanocomposite film with high surface area is created, preventing further growth of HAp due to the unavailability of free $\mathrm{PO}_{4}{ }^{3-}$ ions in the solution. On the other hand, a lower amount of precursor (25HAp) provides less nucleation sites, but also more growth space due to the less dense solution, and, thus, the formation of larger HAp

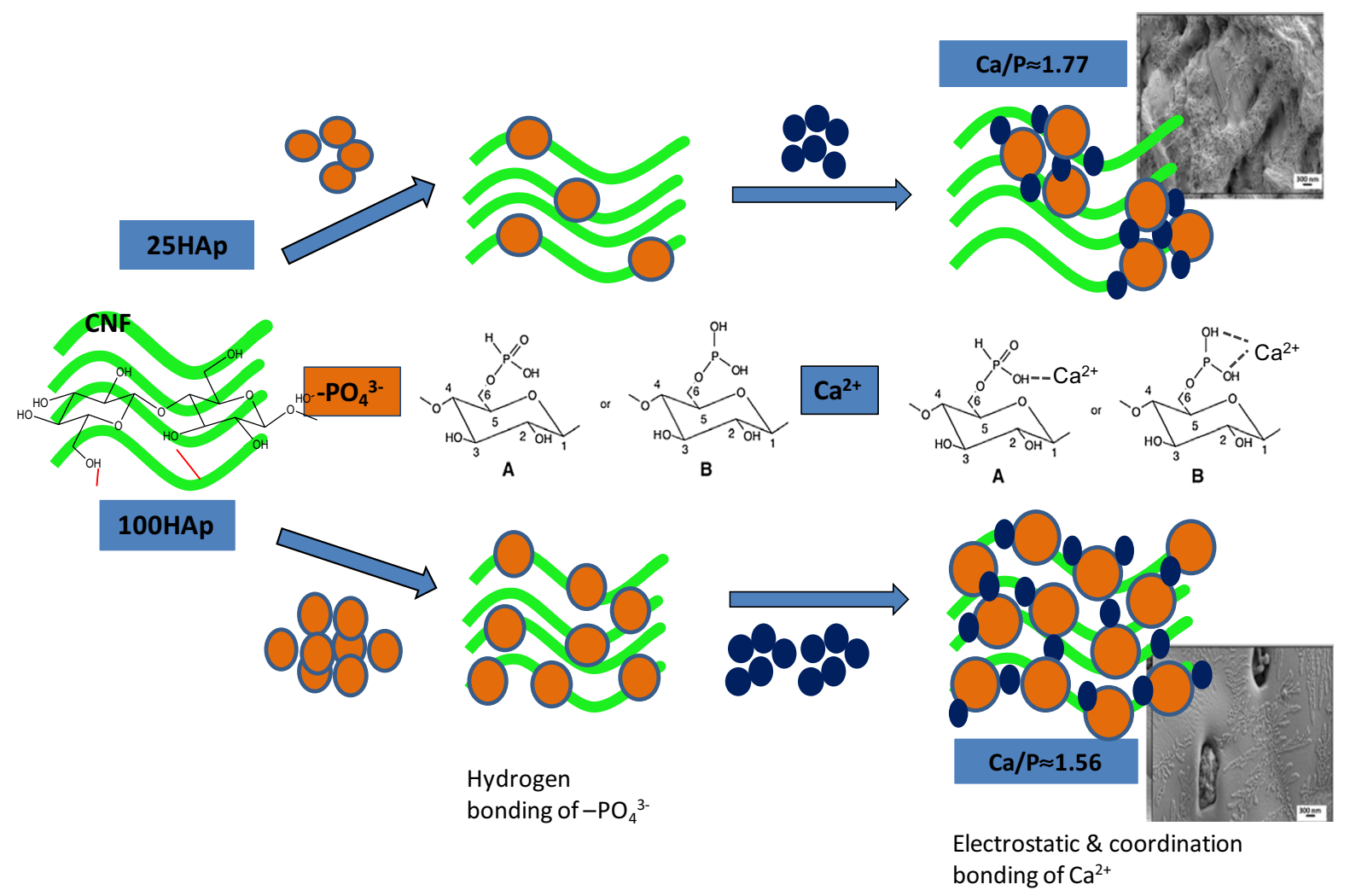

Fig. 3 Schematic illustration of estimated mechanism for HAp structure formation on CNFs 
particles with calcium-richer $(\mathrm{Ca} / \mathrm{P}=1.77)$ or stoichiometric $(\mathrm{Ca} / \mathrm{P}=1.65)$ HAp structure, depending on the CNF content ( $0.5 \mathrm{CNF}$ or $1.5 \mathrm{CNF})$.

The miliQ-water contact angle and absorption ability measurements (Fig. 4) of differently prepared films were performed to support the above discussed phenomena, indicating indirectly also on the films surface wetting properties. As may be observed from the graph in Fig. 4a, the water contact angle of the $0.5 \mathrm{CNF}$ film was found to be a bit lower compared to the pure $1.5 \mathrm{CNF}$ film $\left(\sim 49^{\circ}\right.$ vs. $\left.\sim 52^{\circ}\right)$, which not only suggests lower hydrophilicity of the $1.5 \mathrm{CNF}$ film, but also reveals its surface microstructure properties, being more dense and rough (supported by SEM images in Fig. 2), resulting in the heterogeneous wetting and, thus, the formation of air compartments between the droplets and the substrate. However, the
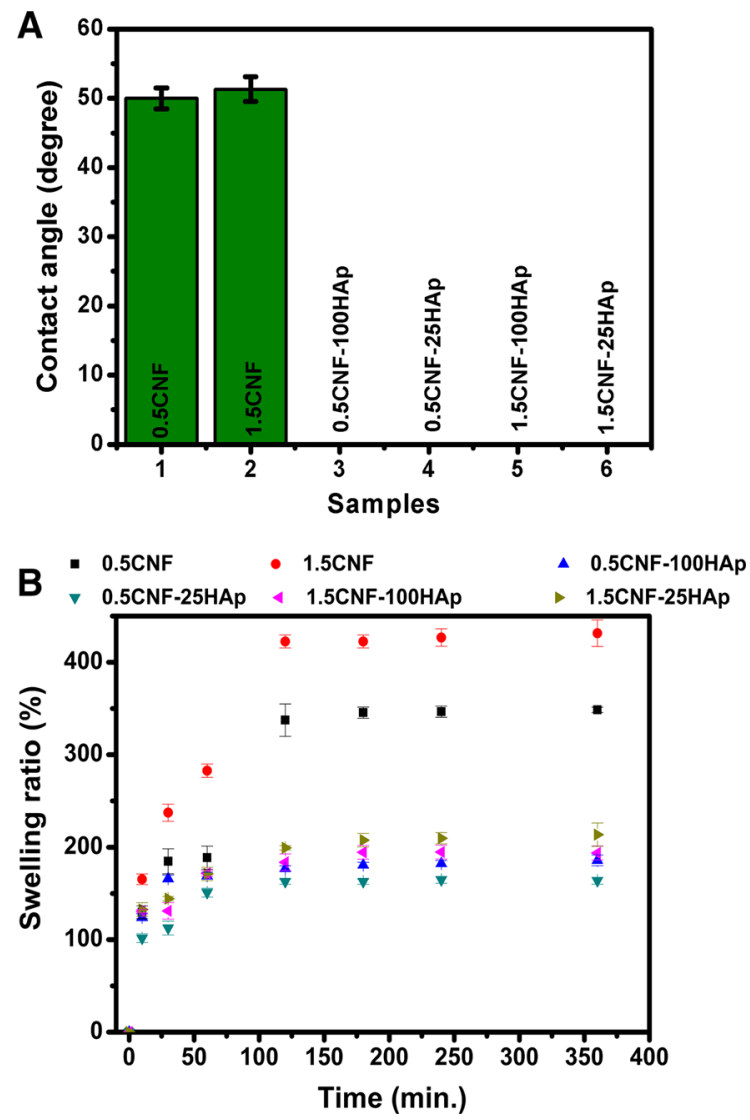

Fig. 4 The water a contact angle and b swelling kinetic for differently prepared CNF and CNF-HAp films, determined at room temperature water droplets get percolated completely through the CNF-HAp films' surface, thereby indicating the super-hydrophilic nature of these films. This may be related both to differently nano-to-micro structured parts of the CNF-HAp films (depending on the CNFs weight mass and the HA structure formed), as well as less- or no- interactive HAp surface with water molecules resulting in their high diffusion (depending also on the H-bonding and orientation of water molecules with the HAp crystal structure, Prakash et al. 2001) and, thus, faster transport through the film, compared to the native CNFs with a huge amount of ionically-dissociated $-\mathrm{OH}$ groups interacting with water molecules and influencing its high swelling properties. Accordingly, the CNF-HAp films swell-up mach less compared to the native CNF films (Fig. 4b).
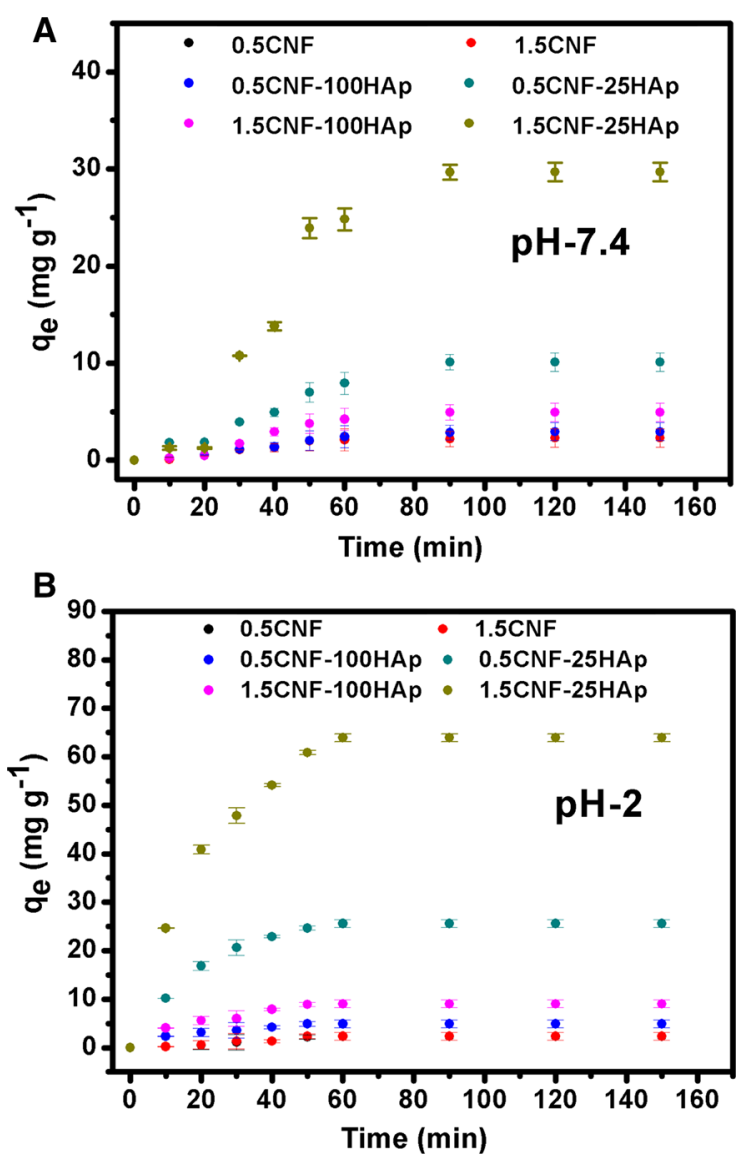

Fig. 5 The effect of $\mathrm{pH}$ and contact time on phenol adsorption capacity for differently prepared CNF and CNF-HAp films, evaluated at room temperature 

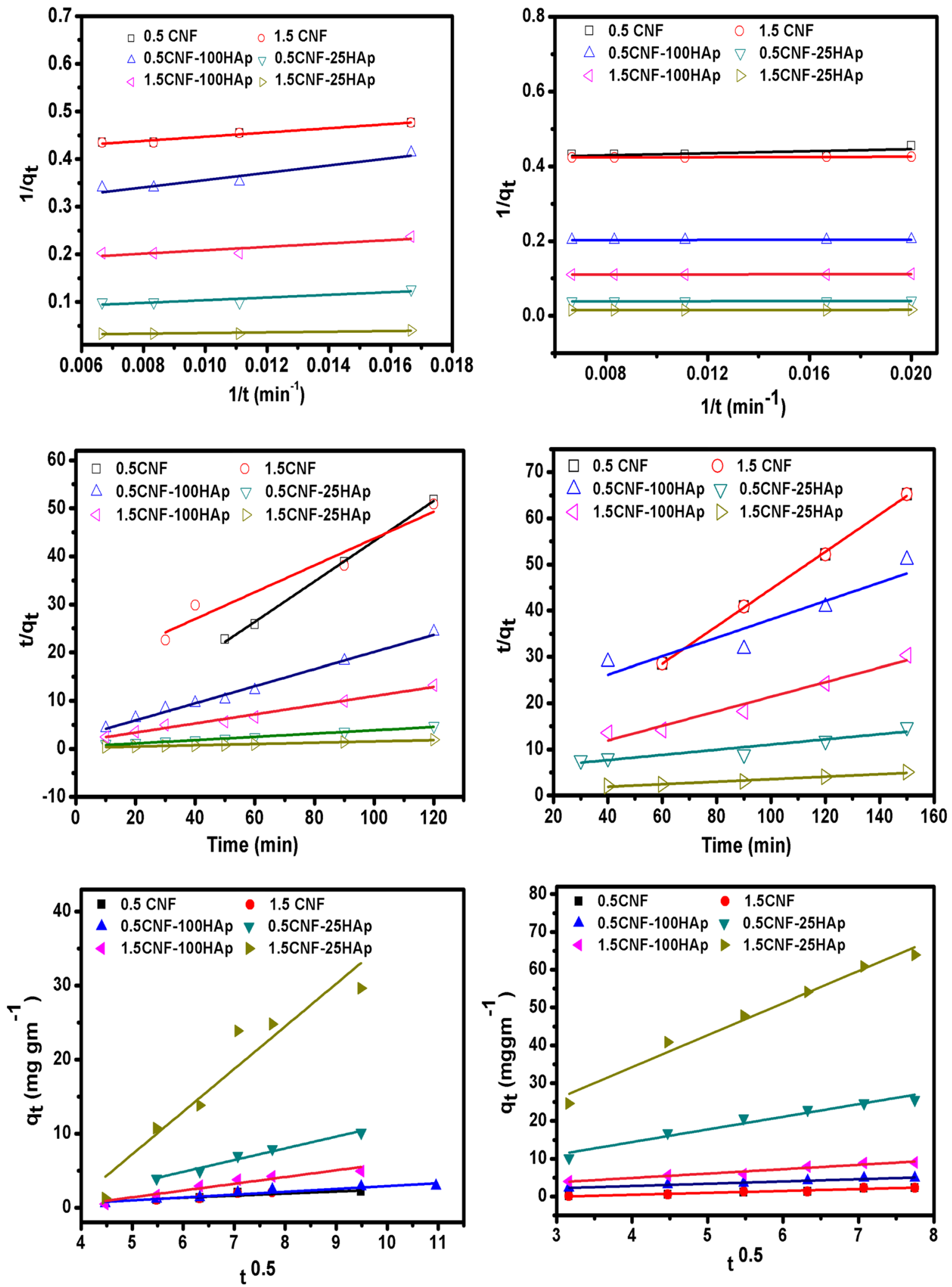
4Fig. 6 The pseudo-first order and pseudo-second order adsorption kinetics for phenol adsorption on differently prepared CNF and CNF-HAp films at $\mathrm{pH} 7.4$ (left) and $\mathrm{pH} 2$ (right), and corresponding intra-particle diffusion plots

\section{Phenol adsorption analysis}

\section{Adsorption equilibrium}

The $\mathrm{pH}$ of a solution is an important parameter influencing the sorption process at the adsorbatesubstrate interfaces. The capacity of phenol adsorption and related kinetics of CNF-HAp films is thus followed in a phenol solution with $\mathrm{pH} 7.4$ (as prepared) and a highly acidic solution of $\mathrm{pH} 2$, as presented in Fig. 5. In both cases, the composite films with lower concentration of HAp precursors show higher adsorption capacity compared to the other two CNF-HAp films, whereas the pure CNF films, as well as pure HAp synthesised, show no or meagre adsorption (max up to $6.1 \mathrm{mg} \mathrm{g}^{-1}$ for HAp at $\mathrm{pH} 2$; data not provided here). At $\mathrm{pH} 2$, the equilibrium value is also reached faster (in about $60 \mathrm{~min}$ ) compared to $\mathrm{pH} 7.4$ (in about $90 \mathrm{~min}$ ). The maximum adsorption capacity in both $\mathrm{pHs}$ was the highest for the 1.5CNF-25HAp film, namely $29.69 \mathrm{mg} \mathrm{g}^{-1}$ (at $7.4 \mathrm{pH}$ ) and $63.94 \mathrm{mg} \mathrm{g}^{-1}$ (at $\mathrm{pH}$ 2), which is relatively high and comparable with many of the other adsorbent materials that have been studied.

Phenol dissolves in water to form phenoxide ions possessing partial negative charge. In the case of the solution of $\mathrm{pH} 7.4, \mathrm{Ca}^{2+}$ ions are attached mainly coordinately with the $\mathrm{PO}_{4}{ }^{3-}$ groups on CNFs, as shown in the proposed mechanism (Fig. 3) and, hence, not available for binding with phenoxide, resulting in lower adsorption capacity. In the case of $\mathrm{pH} 2$, various types of reactions between the phenolic molecule and the film can take place, which causes drastic changes in the surface chemistry of CNF-HAp films. During these reactions, depending on the solution conditions, some different sites can be formed on the mineral surface (Hokkanen et al. 2016b):

$$
\begin{aligned}
& =\mathrm{OH}^{-}+\mathrm{H}^{+} \Rightarrow \mathrm{OH}_{2}^{+} \\
& =\mathrm{PO}_{4}^{3-} \Rightarrow \mathrm{HPO}_{4}^{-} \\
& =\mathrm{HPO}_{4}^{-}+\mathrm{H}^{+} \Rightarrow \mathrm{H}_{2} \mathrm{PO}_{4}^{-} \\
& =\mathrm{Ca}^{2+}+\mathrm{OH}^{-} \Rightarrow \mathrm{CaOH} \\
& =\mathrm{PO}_{4}^{3-}+\mathrm{Ca}^{2+} \Rightarrow \mathrm{PO}_{4} \mathrm{Ca} \\
& =\mathrm{HPO}_{4}^{-}+\mathrm{Ca}^{2+} \Rightarrow \mathrm{HPO}_{4} \mathrm{Ca}^{2+}
\end{aligned}
$$

It is reported that the material exhibits more positive charges while forming HAp with a starting solution of $\mathrm{pH} \leq 3$. Along with this, under lower $\mathrm{pH}$ conditions, HAp is becoming more protonated by the predomination of $\mathrm{Ca}^{2+}$ sites, being favourable for phenol adsorption, while, in contrast, in a light alkaline solution the film surface becomes more negative due to the neutral $\mathrm{CaOH}$ groups and negatively charged phosphate species that predominate under those conditions. However, the sorption capacities of the films for phenols depends not only on the solution $\mathrm{pH}$ value, contact time and ionic species available for the interactions, but are also ascribed to the porous structure (density) of nanocomposite network being related to the content of $\mathrm{CNF}$, as well as the crystalline structure of HAp and its particle-size formed on the CNF surface. The more porous film surfaces can serve as ion channels, and thus may increase ionic interactions with the phenol molecules. In addition, HAp with inserted low crystallinity may possess many lattice defects, which can serve as active sites to absorb phenols chemically as in the case of highly adsorbable 1.5CNF-25HAp film.

\section{Adsorption kinetic and diffusion}

The pseudo-first order and pseudo-second order kinetic models were used to investigate the mechanism of adsorption, being expressed by

$$
\begin{aligned}
& \frac{1}{\mathrm{q}_{\mathrm{t}}}=\frac{\mathrm{k}_{1}}{\mathrm{q}_{1}} \frac{1}{\mathrm{t}}+\frac{1}{\mathrm{q}_{1}} . \\
& \frac{\mathrm{t}}{\mathrm{q}_{\mathrm{t}}}=\frac{1}{\mathrm{k}_{2} \mathrm{q}_{2}^{2}+\frac{\mathrm{t}}{\mathrm{q}_{2}}} .
\end{aligned}
$$

where $\mathrm{q}_{1}, \mathrm{q}_{2}$ and $\mathrm{q}_{\mathrm{t}}$ are amounts of phenol adsorbed $\left(\mathrm{mg} \mathrm{g}^{-1}\right)$ at equilibrium and at time $\mathrm{t}(\mathrm{min}), \mathrm{k}_{1}\left(\mathrm{~min}^{-1}\right)$ and $\mathrm{k}_{2}\left(\mathrm{~g} \mathrm{mg}^{-1} \mathrm{~min}^{-1}\right)$ are the pseudo-first and pseudo-second order rate constants, respectively (Narwade et al. 2017). The pseudo-first order and pseudosecond order adsorption kinetics for phenol at different $\mathrm{pH}$ are presented in Fig. 6, and the fitting parameters of adsorption kinetics at both $\mathrm{pHs}$ are listed in Tables 3 and 4. The data proposes that the phenol adsorption kinetics of all films and at both $\mathrm{pHs}$ follow the pseudo-second order model, since the correlation coefficient $\left(R^{2}>0.99\right)$ obtained by this model was very near to the ideal value of 1 , compared 
Table 3 Adsorption kinetic and diffusion parameters for differently prepared CNF and CNF-HAp films at room temperature and pH 7.4

\begin{tabular}{|c|c|c|c|c|c|c|c|}
\hline Model & Parameters & $0.5 \mathrm{CNF}$ & $1.5 \mathrm{CNF}$ & $\begin{array}{l}0.5 \mathrm{CNF}- \\
\text { 100HAp }\end{array}$ & $\begin{array}{l}0.5 \mathrm{CNF}- \\
25 \mathrm{HAp}\end{array}$ & $\begin{array}{l}1.5 \mathrm{CNF}- \\
100 \mathrm{HAp}\end{array}$ & $\begin{array}{l}1.5 \mathrm{CNF}- \\
25 \mathrm{HAp}\end{array}$ \\
\hline Exp. value & $\mathrm{q}_{\max }\left(\mathrm{mg} \mathrm{g}^{-1}\right)$ & 2.3 & 2.3 & 2.94 & 10.11 & 4.94 & 29.69 \\
\hline \multirow[t]{3}{*}{ Pseudo-first order } & $\mathrm{q}_{1}\left(\mathrm{mg} \mathrm{g}^{-1}\right)$ & 2.48 & 2.48 & 3.57 & 13.23 & 5.78 & 35.68 \\
\hline & $\mathrm{k}_{1}\left(\min ^{-1}\right)$ & 11.01 & 11.01 & 27.40 & 37.27 & 20.71 & 24.45 \\
\hline & $\mathrm{R}^{2}$ & 0.95 & 0.95 & 0.88 & 0.73 & 0.73 & 0.74 \\
\hline \multirow[t]{3}{*}{ Pseudo-second order } & $\mathrm{q}_{2}\left(\mathrm{mg} \mathrm{g}^{-1}\right)$ & 2.47 & 2.47 & 5.02 & 17.83 & 6.34 & 36.81 \\
\hline & $\mathrm{k}_{2}\left(\mathrm{~g} \mathrm{mg}^{-1} \min ^{-1}\right)$ & 0.0379 & 0.0379 & 0.0022 & 0.0006 & 0.0044 & 0.0009 \\
\hline & $\mathrm{R}^{2}$ & 0.99 & 0.99 & 0.81 & 0.85 & 0.95 & 0.97 \\
\hline \multirow[t]{3}{*}{ Intra-particle diffusion } & $\mathrm{C}$ & 0.30 & 1.63 & 0.93 & 4.67 & 3.15 & 21.59 \\
\hline & $\mathrm{k}_{\mathrm{p}}$ & 0.27 & 0.48 & 0.38 & 1.58 & 0.91 & 5.76 \\
\hline & $\mathrm{R}^{2}$ & 0.70 & 0.87 & 0.90 & 0.96 & 0.91 & 0.89 \\
\hline
\end{tabular}

Table 4 Adsorption kinetic and diffusion parameters for differently prepared CNF and CNF-HAp films at room temperature and $\mathrm{pH}$ 2

\begin{tabular}{|c|c|c|c|c|c|c|c|}
\hline Model & Parameters & $0.5 \mathrm{CNF}$ & $1.5 \mathrm{CNF}$ & $\begin{array}{l}0.5 \mathrm{CNF}- \\
100 \mathrm{HAp}\end{array}$ & $\begin{array}{l}0.5 \mathrm{CNF}- \\
25 \mathrm{HAp}\end{array}$ & $\begin{array}{l}1.5 \mathrm{CNF}- \\
100 \mathrm{HAp}\end{array}$ & $\begin{array}{l}1.5 \mathrm{CNF} \\
25 \mathrm{HAp}\end{array}$ \\
\hline Exp. value & $\mathrm{q}_{\max }\left(\mathrm{mg} \mathrm{g}^{-1}\right)$ & 2.32 & 2.36 & 4.93 & 25.58 & 9.04 & 63.94 \\
\hline \multirow[t]{3}{*}{ Pseudo-first order } & $\mathrm{q}_{1}\left(\mathrm{mg} \mathrm{g}^{-1}\right)$ & 2.38 & 2.36 & 4.95 & 26.09 & 9.12 & 65.70 \\
\hline & $\mathrm{k}_{1}\left(\min ^{-1}\right)$ & 3.29 & 0.38 & 0.48 & 2.20 & 0.99 & 3.02 \\
\hline & $\mathrm{R}^{2}$ & 0.39 & 0.83 & 0.39 & 0.39 & 0.39 & 0.39 \\
\hline \multirow[t]{3}{*}{ Pseudo-second order } & $\mathrm{q}_{2}\left(\mathrm{mg} \mathrm{g}^{-1}\right)$ & 2.38 & 3.58 & 5.63 & 29.27 & 10.53 & 74.62 \\
\hline & $\mathrm{k}_{2}\left(\mathrm{~g} \mathrm{mg}^{-1} \min ^{-1}\right)$ & 0.142 & 0.0049 & 0.0131 & 0.0025 & 0.0060 & 0.0008 \\
\hline & $\mathrm{R}^{2}$ & 0.99 & 0.92 & 0.98 & 0.98 & 0.98 & 0.98 \\
\hline \multirow[t]{3}{*}{ Intra-particle diffusion } & $\mathrm{C}$ & 1.53 & 1.52 & 0.42 & 1.07 & 0.31 & 0.45 \\
\hline & $\mathrm{k}_{\mathrm{p}}$ & 0.493 & 0.504 & 0.599 & 3.340 & 1.156 & 8.453 \\
\hline & $\mathrm{R}^{2}$ & 0.942 & 0.919 & 0.978 & 0.949 & 0.954 & 0.977 \\
\hline
\end{tabular}

to that obtained for the first-order model. The obtained parameters from kinetic models were found to correlate with the data determined experimentally.

It can also be concluded that the correlation coefficient $\left(\mathrm{R}^{2}\right)$ is closer to an ideal value in the case of 1.5CNF-25HAp and 1.5CNF-100HAp films with the higher CNFs concentration at $\mathrm{pH} 7.4$, while it fits very well to this model for all films at $\mathrm{pH} 2$. The kinetic parameters, obtained through the second kinetic model, are also similar to actual experimental results.

The intra-particle diffusion model was taken into account in order to identify the phenol diffusion mechanism. This model is expressed by the Weber and Morris equation (Lin et al. 2009): $\mathrm{q}=\mathrm{k}_{\mathrm{p}} \mathrm{t}^{0.5}+\mathrm{C}$

where $\mathrm{C}$ is the intercept $\left(\mathrm{mg} . \mathrm{g}^{-1}\right)$ associated with the diffusion boundary layer thickness and $\mathrm{k}_{\mathrm{p}}$ is the intraparticle diffusion rate constant $\left(\mathrm{mg} \mathrm{g}^{-1} \mathrm{~min}^{1 / 2}\right)$ of adsorption step $\mathrm{p}$, which is estimated from the straight line of $\mathrm{q}_{\mathrm{t}}$ versus $\mathrm{t}^{0.5}$. According to this model, the intraparticle diffusion is the rate limiting step of the entire adsorption process; the plots of $\mathrm{q}_{\mathrm{t}}$ versus $\mathrm{t}^{0.5}$ yield a straight line passing through the origin. The values of $k_{\mathrm{p}}$ and $C$ were determined from the slopes of the linear plots, and the constants of the intra-particle diffusion model at both $\mathrm{pHs}$ are given in Tables 4 and 5, respectively. All the CNF-HAp samples show 


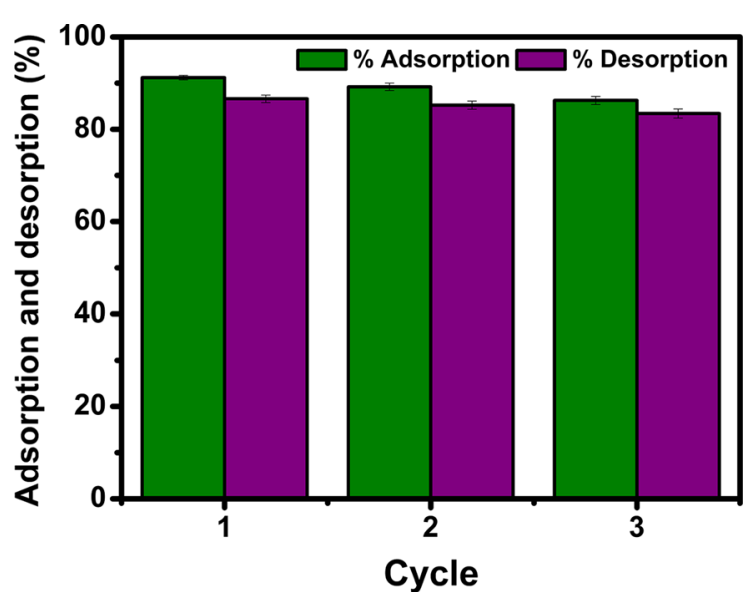

Fig. 7 Adsorption-desorption cycles of phenol at $\mathrm{pH} 2$ for 1.5CNF-25HAp film

positive intercept $(\mathrm{C})$, thereby also indicating phenol adsorption via the intra-diffusion process, being the fastest (with maximum $\mathrm{k}_{\mathrm{p}}$ ) for $1.5 \mathrm{CNF}-25 \mathrm{HAp}$ film.

\section{Desorption and regeneration study}

The regeneration of adsorbent is an important factor which affects the overall cost of the adsorption process and sustainable applications. In this framework, the phenol desorption from the 1.5CNF-25HAp film was performed by incubating the sample in MiliQ water for up to $3 \mathrm{~h}$, and the adsorption capacity of regenerated film was investigated for three repeated experiments. The desorption equilibrium time observed for this film was recorded to be between 150 and $170 \mathrm{~min}$. As seen from Fig. 7, even though the adsorption capacity of regenerated film decreased slightly during three sequential adsorption-desorption cycles, the adsorption efficiency was still about $86 \%$ of its initial value after regeneration, demonstrating that film is a benign sustainable adsorbent.

\section{Conclusion}

Novel bio-based CNF-HAp composite films were prepared in situ by the wet-chemical precipitation method using different concentrations of HAp precursor and weight mass of CNFs, and evaluated for the removal of phenol from aqueous solutions of different pHs. The results revealed that the size of the HAp particles formed on the CNFs' surface and its crystallite structure is dependent primarily on the concentration of precursors and, secondly, on the CNFs' weight mass, being reflected in a porous and rough surface with unevenly distributed and calciumricher HAp particles, or a smoother, phosphate-richer or stoichiometric apatite and layered-type structure on the CNFs' surface with more dense and homogenously distributed HAp. It is also observed that such a structure also influences the super-hydrophilic nature of the films that increases the diffusion and faster transport of water molecules through the film, with negligible swelling, while interacting with the phenol molecules. Besides the film's structure, the solution $\mathrm{pH}$ also played a significant role in the capacity of adsorption towards phenol molecules. An acidic solution led to a significant increase in the adsorption capacity on the positively-charged calcium-richer HAp-structured CNFs' surface, which followed the pseudo-second order kinetic and intra-particle diffusion model of adsorption. The highly-effective reusing ability of the films indicates additionally their high added-value properties, which may be exploited in the wastewater purification as film adsorbents or, potentially, filter membranes.

Acknowledgments The authors are thankful to the Erasmus Mundus Project Euphrates (2013-2540/001-001-EMA2) for financial support.

Open Access This article is distributed under the terms of the Creative Commons Attribution 4.0 International License (http:// creativecommons.org/licenses/by/4.0/), which permits unrestricted use, distribution, and reproduction in any medium, provided you give appropriate credit to the original author(s) and the source, provide a link to the Creative Commons license, and indicate if changes were made.

\section{References}

Abe K, Iwamoto S, Yano H (2007) Obtaining cellulose nanofibers with a uniform width of $15 \mathrm{~nm}$ from wood. Biomacromol 8(10):3276-3278

Ahmaruzzaman M (2005) Adsorption of phenolic compounds on low-cost adsorbents: a review. Adv Colloid Interface Sci 143(1):48-67

Ahmaruzzaman M, Sharma DK (2005) Adsorption of phenols from wastewater. J Colloid Interface Sci 287(1):14-24

Ajeel MA, Aroua MK, Daud WM, Mazari SA (2017) Effect of adsorption and passivation phenomena on the electrochemical oxidation of phenol and 2-chlorophenol at carbon black diamond composite electrode. Ind Eng Chem Res 56(6):1652-1660 
Banat FA, Al-Bashir B, Al-Asheh S, Hayajneh O (2000) Adsorption of phenol by bentonite. Environ Pollut 107(3):391-398

Božič M, Liu P, Mathew AP, Kokol V (2014) Enzymatic phosphorylation of cellulose nanofibers to new highly-ions adsorbing, flame-retardant and hydroxyapatite-growth induced natural nanoparticles. Cellulose 21(4):2713-2726

Bruce RM, Santodonato J, Neal MW (1987) Summary review of the health effects associated with phenol. Toxicol Ind Health 3(4):535-568

Caetano M, Valderrama C, Farran A, Cortina JL (2009) Phenol removal from aqueous solution by adsorption and ion exchange mechanisms onto polymeric resins. J Colloid Interface Sci 338(2):402-409

Chaudhary N, Balomajumder C (2014) Optimization study of adsorption parameters for removal of phenol on aluminum impregnated fly ash using response surface methodology. J Taiwan Inst Chem Eng 45(3):852-859

Chavan PN, Bahir MM, Mene RU, Mahabole MP, Khairnar RS (2010) Study of nanobiomaterial hydroxyapatite in simulated body fluid: formation and growth of apatite. Mater Sci Eng B 168(1):224-230

Corami A, Mignardi S, Ferrini V (2008) Cadmium removal from single-and multi-metal $(\mathrm{Cd}+\mathrm{Pb}+\mathrm{Zn}+\mathrm{Cu})$ solutions by sorption on hydroxyapatite. J Colloid Interface Sci 317(2):402-408

Dąbrowski A, Podkościelny P, Hubicki Z, Barczak M (2005) Adsorption of phenolic compounds by activated carbon-a critical review. Chemosphere 58(8):1049-1070

Daud WR, Kassim MH, Mohamded MA (2011) Cellulose phosphate from oil palm biomass as potential biomaterials. BioResources 6(2):1719-1740

Dhorabe PT, Lataye DH, Ingole RS (2016a) Adsorptive removal of 4-nitrophenol from aqueous solution by activated carbon prepared from waste orange peels. J Hazard Toxic Radioact Waste 15:04016015

Dhorabe PT, Lataye DH, Ingole RS (2016b) Removal of 4-nitrophenol from aqueous solution by adsorption onto activated carbon prepared from Acacia glauca sawdust. Water Sci Technol 73(4):955-966

Din AT, Hameed BH, Ahmad AL (2009) Batch adsorption of phenol onto physiochemical-activated coconut shell. J Hazard Mater 161(2):1522-1529

Dufresne A (2013) Nanocellulose: a new ageless bionanomaterial. Mater Today 16(6):220-227

Dursun AY, Kalayci CS (2005) Equilibrium, kinetic and thermodynamic studies on the adsorption of phenol onto chitin. J Hazard Mater 123(1):151-157

Dursun G, Çiçek H, Dursun AY (2005) Adsorption of phenol from aqueous solution by using carbonised beet pulp. J Hazard Mater 125(1):175-182

Ehrhardt HM, Rehm HJ (1985) Phenol degradation by microorganisms adsorbed on activated carbon. Appl Microbiol Biotechnol 21(1):32-36

Esplugas S, Gimenez J, Contreras S, Pascual E, Rodríguez M (2002) Comparison of different advanced oxidation processes for phenol degradation. Water Res 36(4):1034-1042

Fang W, Zhang H, Yin J, Yang B, Zhang Y, Li J, Yao F (2016) Hydroxyapatite crystal formation in the presence of polysaccharide. Cryst Growth Des 16(3):1247-1255
Feng Y, Gong JL, Zeng GM, Niu QY, Zhang HY, Niu CG, Deng JH, Yan M (2010) Adsorption of Cd (II) and Zn (II) from aqueous solutions using magnetic hydroxyapatite nanoparticles as adsorbents. Chem Eng J 162(2):487-494

Gopakumar DA, Pasquini D, Henrique MA, de Morais LC, Grohens Y, Thomas S (2017) Meldrum's acid modified cellulose nanofiber-based polyvinylidene fluoride microfiltration membrane for dye water treatment and nanoparticle removal. ACS Sustain Chem Eng 5(2):2026-2033

Gupta VK, Ali I, Saini VK (2004) Removal of chlorophenols from wastewater using red mud: an aluminum industry waste. Environ Sci Technol 38(14):4012-4018

Hokkanen S, Repo E, Westholm LJ, Lou S, Sainio T, Sillanpää $\mathrm{M}$ (2014) Adsorption of $\mathrm{Ni}^{2+}, \mathrm{Cd}^{2+}, \mathrm{PO}_{4}{ }^{3-}$ and $\mathrm{NO}^{3-}$ from aqueous solutions by nanostructured microfibrillated cellulose modified with carbonated hydroxyapatite. Chem Eng J 252:64-74

Hokkanen S, Bhatnagar A, Sillanpää M (2016a) A review on modification methods to cellulose-based adsorbents to improve adsorption capacity. Water Res 91:156-173

Hokkanen S, Bhatnagar A, Repo E, Lou S, Sillanpää M (2016b) Calcium hydroxyapatite microfibrillated cellulose composite as a potential adsorbent for the removal of $\mathrm{Cr}(\mathrm{VI})$ from aqueous solution. Chem Eng J 283:445-452

Ingole RS, Lataye DH (2013) Adsorptive removal of phenol from aqueous solution using activated carbon prepared from babul sawdust. J Hazard Toxic Radioact Waste 19(4):04015002

Ingole RS, Lataye DH, Dhorabe PT (2017) Adsorption of phenol onto banana peels activated carbon. KSCE J Civil Eng 21(1):100-110

Jain AK, Gupta VK, Jain S, Suhas (2004) Removal of chlorophenols using industrial wastes. Environ Sci Technol 38(4):1195-1200

Juang RS, Shiau JY (1999) Adsorption isotherms of phenols from water onto macroreticular resins. J Hazard Mater 70(3):171-183

Kilic M, Apaydin-Varol E, Pütün AE (2011) Adsorptive removal of phenol from aqueous solutions on activated carbon prepared from tobacco residues: equilibrium, kinetics and thermodynamics. J Hazard Mater 189(1):397-403

Kokol V, Božič M, Vogrinčič R, Mathew AP (2015) Characterisation and properties of homo-and heterogeneously phosphorylated nanocellulose. Carbohydr Polym 125:301-313

Koyama O, Kamagata Y, Nakamura K (1994) Degradation of chlorinated aromatics by Fenton oxidation and methanogenic digester sludge. Water Res 28(4):895-899

Kumar A, Kumar S, Kumar S, Gupta DV (2007) Adsorption of phenol and 4-nitrophenol on granular activated carbon in basal salt medium: equilibrium and kinetics. J Hazard Mater 147(1):155-166

Lei Y, Chen W, Lu B, Ke QF, Guo YP (2015) Bioinspired fabrication and lead adsorption property of nano-hydroxyapatite/chitosan porous materials. RSC Adv 120:98783-98795

Li Z, Li X, Xi H, Hua B (2002) Effects of ultrasound on adsorption equilibrium of phenol on polymeric adsorption resin. Chem Eng J 86(3):375-379 
Li JM, Meng XG, Hu CW, Du J (2009) Adsorption of phenol, p-chlorophenol and p-nitrophenol onto functional chitosan. Biores Technol 100(3):1168-1173

Li J, Liu Q, Liu Y, Xie J (2017) Development of electro-active forward osmosis membranes to remove phenolic compounds and reject salts. Environ Sci Water Res Technol 3(1):139-146

Lin SH, Juang RS (2009) Adsorption of phenol and its derivatives from water using synthetic resins and low-cost natural adsorbents: a review. J Environ Manag 90(3):1336-1349

Lin K, Pan J, Chen Y, Cheng R, Xu X (2009) Study the adsorption of phenol from aqueous solution on hydroxyapatite nanopowders. J Hazard Mater 161(1):231-240

Lorenc-Grabowska E (2016) Effect of micropore size distribution on phenol adsorption on steam activated carbons. Adsorption 22(4-6):599-607

Mahto TK, Pandey SC, Chandra S, Kumar A, kumar Sahu S (2015) Hydroxyapatite conjugated graphene oxide nanocomposite: a new sight for significant applications in adsorption. RSC Adv 5(117):96313-96322

Mangrulkar PA, Kamble SP, Meshram J, Rayalu S (2008) Adsorption of phenol and o-chlorophenol by mesoporous MCM-41. J Hazard Mater 160(2):414-421

Michałowicz J, Duda W (2007) Phenols—sources and toxicity. Pol J Environ Stud 16(3):347-362

Moon RJ, Martini A, Nairn J, Simonsen J, Youngblood J (2011) Cellulose nanomaterials review: structure, properties and nanocomposites. Chem Soc Rev 40(7):3941-3994

Narwade VN, Khairnar RS (2017) Cobalt adsorption on the nano-hydroxyapatite matrix: isotherm and kinetic studies. Bull Pol Acad Sci Tech 65(2):131-137

Narwade VN, Mahabole MP, Bogle KA, Khairnar RS (2014) Waste water treatment by nanoceramics: removal of Lead particles. Int J Eng Sci Innov Technol 3(3):324-329

Narwade VN, Kokol V, Khairnar RS (2017) Phenol adsorption on graphite-hydroxyapatite nanocomposites: kinetic and Isotherm Study. J Mater Sci Surf Eng 5(2):544-548

Özkaya B (2006) Adsorption and desorption of phenol on activated carbon and a comparison of isotherm models. J Hazard Mater 129(1):158-163

Panda RN, Hsieh MF, Chung RJ, Chin TS (2003) FTIR, XRD, SEM and solid state NMR investigations of carbonatecontaining hydroxyapatite nano-particles synthesized by hydroxide-gel technique. J Phys Chem Solids 64(2):193-199

Prakash M, Lemaire T, Tommaso DD, Leeuw N, Lewerenz M, Caruel M, Naili S (2001) 7) Transport properties of water molecules confined between hydroxyapatite surfaces: a molecular dynamics simulation approach. Appl Surf Sci 418:296-301

Sáenz-Alanís CA, García-Reyes RB, Soto-Regalado E, GarcíaGonzález A (2017) Phenol and methylene blue adsorption on heat-treated activated carbon: characterization, kinetics, and equilibrium studies. Adsorp Sci Technol 25:0263617416684517

Skwarek E, Goncharuk O, Sternik D, Janusz W, Gdula K, Gun'ko VM (2017) Synthesis, structural, and adsorption properties and thermal stability of nanohydroxyapatite/ polysaccharide composites. Nanoscale Res Lett 12(1):155

Smičiklas I, Dimović S, Plećaš I, Mitrić M (2006) Removal of $\mathrm{Co}^{2+}$ from aqueous solutions by hydroxyapatite. Water Res 40(12):2267-2274

Sprynskyy M, Ligor T, Lebedynets M, Buszewski B (2009) Kinetic and equilibrium studies of phenol adsorption by natural and modified forms of the clinoptilolite. J Hazard Mater 169(1):847-854

Srivastava VC, Swamy MM, Mall ID, Prasad B, Mishra IM (2006) Adsorptive removal of phenol by bagasse fly ash and activated carbon: equilibrium, kinetics and thermodynamics. Colloids Surf A Physicochem Eng Asp 272(1):89-104

Vázquez I, Rodriguez-Iglesias J, Maranon E, Castrillón L, Alvarez M (2007) Removal of residual phenols from coke wastewater by adsorption. J Hazard Mater 147(1):395-400

Wen X, Shao CT, Chen W, Lei Y, Ke QF, Guo YP (2016) Mesoporous carbonated hydroxyapatite/chitosan porous materials for removal of $\mathrm{Pb}$ (ii) ions under flow conditions. RSC Adv 6(115):113940-113950

Yang X, Liu X, Tang W, Gao Y, Ni H, Zhang J (2015) A novel hydrothermal releasing synthesis of modified $\mathrm{SiO}_{2}$ material and its application in phenol removal process. Korean $\mathrm{J}$ Chem Eng 32(4): 1

Zaky AM, Chaplin BP (2014) Mechanism of p-substituted phenol oxidation at a $\mathrm{Ti}_{4} \mathrm{O}_{7}$ reactive electrochemical membrane. Environ Sci Technol 48(10):5857-5867

Zhang C, Wang Y, Zhou Y, Guo J, Liu Y (2014) Silica-based surface molecular imprinting for recognition and separation of lysozymes. Anal Methods 6(21):8584-8591

Zhao XY, Zhu YJ, Zhao J, Lu BQ, Chen F, Qi C, Wu J (2014) Hydroxyapatite nanosheet-assembled microspheres: hemoglobin-template synthesis and adsorption for heavy metal ions. J Collaid Inter Sci 416:11-18 